\title{
The Human Organ Transplantation Act in Bangladesh: Towards Proper Family-Based Ethics and Law
}

\author{
Md. Sanwar Siraj ${ }^{1}$ (D)
}

Received: 20 November 2020 / Revised: 20 February 2021 / Accepted: 22 February 2021 /

Published online: 10 April 2021

(c) National University of Singapore and Springer Nature Singapore Pte Ltd. 2021

\section{Abstract}

The Human Organ Transplantation Act came into officially force in Bangladesh on April 13, 1999, allowing organ donations from both living and brain-dead donors. The Act was amended by the Parliament on January 8, 2018, with the changes coming into effect shortly afterwards on January 28 . The Act was revised to extend a living donor pool from close relatives (e.g., parents, adult sons and daughters, adult brothers and sisters, uncles and aunts from both the paternal and maternal sides, and spouses) to include certain other relatives such as grandparents, grandchildren, and first cousins (Section 2:4). The Act was also revised to allow individuals to prioritize family members in receiving their organs after their death (Section 7c:3). The aim of this paper is not to carry out an ethical analysis of the Act as a whole but only to focus on aspects relating to priority access for family members to organs. Despite Islam encouraging Muslims to be sympathetic, and to save the life of any member of humankind (Quran 5:32), saving the life of a relative through organ donation is even more highly valued. The collective and extended structure of the family impacts on the provisions of the Act that only allows Bangladeshis to legally donate their organs to save the lives of relatives and allows individuals to prioritize family members. Recent progress in the practice of organ transplantation raises a number of ethical dilemmas around the allocation of available organs in the context of organ scarcity. A key purpose of introducing incentive into the system of organ allocation is to increase the number of donations from living relatives and initiation of vital organ donations from brain-dead donors. However, allocation criteria based on a living organ donation incentive system would appear to be unethical because there is no provision in the Act with regard to financial compensation for a distant relative donor's post-operative care in the absence of healthcare coverage. Receiving organs from a distant relative without giving financial compensation for post-operative care places them in a grave health condition and violates the biomedical principle of non-maleficence. An incentive system around brain-dead donors

Md. Sanwar Siraj

siraj_sanwar@yahoo.com

1 Department of Government and Politics, Jahangirnagar University, Dhaka, Bangladesh 
would appear to be ethical as the amended Act allows individuals to prioritize relatives in receiving their organs after death. This provision is intended to initiate the transplantation of vital organs (e.g., kidney, liver, heart, pancreas, bone marrow) from brain-dead donors as families might bear the cost of keeping the organs alive for transplantation. Regular reassessment of the impact of the Act is necessary to maximize the donation rate of transplantable organs using ethical means.

Keywords Organ transplantation · Brain death · Living donation · Organ allocation · Bangladesh

\section{Introduction}

Legal documentation is necessary in a country where healthcare professionals are able to procure organs ethically from possible sources (Bagheri 2005). The Human Organ Transplantation Act came officially into force in Bangladesh, on April 13, 1999, allowing organ donation from both living and brain-dead donors. Religious leaders issued fatwa or religious rulings in favor of organ transplantation. The Act was subsequently amended by the Parliament on January 8, 2018, and approved on January 28. The Act is a legal document that applies to obtaining organs from both brain-dead and living related donors in Bangladesh. The Act was revised to extend a living donor pool from close relatives (e.g., parents, adult sons and daughters, adult brothers and sisters, uncles and aunts from both the paternal and maternal sides, and spouses) to include certain other relatives such as grandparents, grandchildren, and first cousins (Section 2:4). The first successful live-related donor organ transplantation started in Bangladesh in 1982 and became commonplace in 1988. In Bangladesh, the total incidence of legal organ donation from living donors (to related recipients) amounts to nearly 2000 cases of kidney transplantation, in addition to a small number of liver and bone marrow transplants (Siraj 2020; UNB News 2020; bdnews24. com 2017; Ali et al. 2014). The Act was also revised to allow an individual to prioritize family members in receiving their organs after their death (Section 7c:3). Aside from a few posthumous corneal donations, transplantation of vital organs (e.g., kidney, liver, heart, pancreas, bone marrow) from brain-dead donors is still not practiced in Bangladesh (Siraj 2021). Under the amendment, the incentive system of organ allocation was also introduced for the purpose of initiating donations of vital organs (e.g., kidney, liver, heart, pancreas, bone marrow, and any other body parts or organs) from brain-dead donors in Bangladesh.

This paper summarizes the main provisions of the Human Organ Transplantation Act, which fall within the scope of the removal of organs from related living and brain-dead donors. The aim of this paper is not to carry out an ethical analysis of the Act as a whole, but only to focus on aspects relating to priority access for family members to organs.

\section{Methodology}

By reviewing a handful of medical, bioethical, anthropological, sociological, and Islamic religious literature, the aim of the study is to undertake an ethical analysis solely on issues relating to priority access for family members to organs. More 
specifically, this paper is an ethical study of how the Islamic family system affects the provisions of the Act by motivating individuals to legally donate organs to family members for transplantation and to prioritize the receipt of their organs by family relatives after their death.

\section{Summary of the Act}

\section{Purpose and Scope of the Act}

The present Act places legal requirements around the collection and preservation of human organs as well as the legal requirement to ensure their transplantation, and the expedience thereof, into a human body. The Act applies not only to the removal of organs such as the kidneys, heart, liver, pancreas, bone, bone marrow, eyes, skin, and tissue but also to any other organ or tissue from the human body that is transplantable (Section 2:1). Therefore, the Act does not apply to cosmetic surgery or to auto-transplantation for the purposes of one's own treatment.

\section{Removal of Organs from Living Donors}

The Act approves living organ donation for transplantations. The Act prescribes that a living person who is healthy and has the mental capacity can donate his/her organs or body part to a close relative if it is not likely to disrupt their ability to live a normal life (Section 3:1). If the donor and recipient are not close relatives as set out in the Act, donation is not legally allowed. The Act stipulates legal successors defined as husband and wife, adult son and daughter, father and mother, adult brother and sister, and other adult relatives connected by blood such as paternal and maternal uncles and aunts who can donate their organs for transplantation to save the life of the recipient (Section 2:2). The Act defines "close relatives" as the father and mother, adult son and daughter, brother and sister, husband and wife, and paternal and maternal uncle and aunt (Section 2:4). The Act only considered three categories of relative such as (1) first-degree blood relatives, including father and mother, adult son and daughter, brother and sister; (2) second-degree blood relatives, including paternal and maternal uncles and aunts; and (3) non-blood relatives, namely spouses. In order to increase the pool of potential donors, a recent revision of the Act redefines the term close relative and adds grandparents, grandchildren, and first cousins as potential donors (Section 2:4). As such, the Act as it currently stands only approves living donations from close family members, namely the father and mother, adult son and daughter, husband and wife, adult brother and sister, paternal uncle and aunt, maternal uncle and aunt, grandparents, grandchildren, and first cousins. Aside from these relatives, nobody else is legally allowed to donate organs for transplantation in Bangladesh. It also prescribes that the order priority in donating organs for transplantation descends down the aforementioned list (Section 2:2), such that a closer relative is given higher priority in being able to donate their organs than those who are less close. For instance, in the case where a person was eligible to 
receive an organ donation, their son or daughter has priority to donate over that of uncles and aunts.

The Act prohibits the removal of organs from persons aged less than 18 years and over 65 years (Section 6:1b). For regenerated tissue, this condition does not apply if the donor and recipient are brother and sister. It also prescribes that the condition does not apply to transplantation of the eye, skin, tissue, and bone marrow (Section 6:1b). The Act sets exceptions for the eyes, skin, tissue, and bone marrow in that these organs and tissues can be obtained from persons under 18 years old and over 65 years old and can be donated to a person other than the aforementioned list of family relatives (Section 3:1). The removal of these tissues has limited impact on the human body and does not significantly affect the donor's health. Furthermore, with the exception of the eye, these tissues are regenerated. The Act sets age limits for organ recipients; recipients aged between 2 and 70 years are eligible to receive organs, but the priority is given to persons aged between 15 and 50 years (Section 6:2a).

\section{Removal of Organs from Brain-dead Donors}

Under the Act, the term deceased refers to a human body with a heartbeat that has been declared brain-dead by an authorized specialist physician and whose organs have been operated by life support for the purpose of transplantation into another human body (Section 2:3). The Act authorizes a team of physicians to declare brain death. The declaration of brain death committee is usually included in the donor's Determination of Brain Death. The committee is principally composed of three expert physicians with the rank of Professor or Associate Professor in Medicine or Critical Care Medicine, Neurology, and Anesthesiology, as these are the physicians with the ability to declare a person brain-dead (Section 5:1).

The removal of organs from deceased donors is limited to brain-dead donors. Section 4 of the Act prescribes that organs can only be removed from a person after declaring brain death and transplanted into a person, in accordance with Sect. 5, in the following cases: if (a) the donor voluntarily donates any of his/her organs during their lifetime for the purpose of transplantation, or (b) in the absence of such a donation mentioned in clause "a," after the diagnosis of brain death of the said person, if any of their legal heirs gives written permission allowing the organs of the said person to be used in this way, or (c) the dead body is not claimed $24 \mathrm{~h}$ after the diagnosis of brain death, and the person in charge of the administrative authority permits it or (d) in the case of dissection of the eye, skin, and tissue, if the body is in the possession of any other person or institution or place and the relevant Deputy Commissioner or, as the case may be, District Commissioner or person assigned by the District Commissioner authorizes the donation in writing (Section 4:1). The following recipients under the Act will be given priority for receiving organs from the deceased for transplantation: firstly, a person whose brain death is declared has given written consent for the donation of an organ to a close relative or other person during their lifetime; secondly, a person who is relatively young; thirdly, a person near death where the procedure would likely save their life; and finally a person who 
is at a relatively nearby geographically or a short travel time away. These conditions are subject to successful cross-matching of the donor and recipient on the register (Section 7c:3). Information of patients eligible for receiving organ transplantation and persons declared brain-dead and eligible for donating organs is kept in every hospital where transplantations are regularly conducted (Section 8:1). In this way, the Act provides an opportunity for all who are in need of organ donation, but gives priority to the wishes of the brain-dead donor's family.

The Act prohibits the selling of organs or receiving any financial benefits in exchange for organs. Selling and buying of human organs means receiving any financial benefits for exchanging organs or agreement to do so. The Act also completely bans advertisements, including newspaper classifieds, for the purpose of selling organs. It also prohibits financial dealings related to the exchange of human organs and forbids any other campaigns related to selling organs (Section 9). However, financial reimbursement including fees for surgery, transplantation, in-patient hospitalization during recovery, loss of earnings, post-operative care and medication, Intensive Care Unit (ICU) access and ventilators, burial or funereal services, and corpse transportation are not interpreted in any clauses of the Act.

\section{Recent Progress in Organ Allocation: Ethical Dilemmas}

Before analyzing ethical issues in regard to the organ allocation for the purpose of transplantation, there must first be a discussion about the nature of the family in the context of a Bangladeshi majority Muslim society and collective culture. The longstanding homogenous cultural tradition and Islamic religious values shape collectivistic familial structure in Bangladesh. The collectivistic characteristic of the family reinforces the familial bond between individuals and integrates them coherently in an extended familial structure. Similar to many traditional and Muslim cultures throughout the world (Fan 2015; Moazam 2006), a common belief for Bangladeshis is that people are social human beings, so they are naturally and mutually dependent on each other in families from the moment of their birth. Because the family is the fundamental institution among other institutions in Muslim society where each individual is born, nurtured, grows up, lives, and dies within the familial structure. Each individual customarily and traditionally learned and nurtured Islamic religious values and customs within the familial structure in their daily lives (Dhami and Sheikh 2000). This ethos has assisted Bangladeshis in developing and maintaining a collectivistic behavioral pattern of familial life. This societal ethos ultimately allows Bangladeshis to share joy and grief collectively within the family and to reinforce the collective interest and well-being. If someone is vulnerable, others help them financially, offer them food, and take care of them. If someone were to need an organ transplant, other family members would donate their organs willingly.

The kinship relationship among family members is strong and plays a significant role in providing a sense of common belonging, harmony, and mutual safety. The "family" is often thought of as including many members of the extended family, and often, multiple families are "joined." In this way, the extended family network works as a bridge among generations or to multiple nuclear families. Similar 
to South Asian Muslim societies (Moazam 2006), Bangladeshi families are traditional and often comprise three or more generations living together under the same roof or in close proximity. Bangladeshi families are not typically a nuclear family comprising only a husband, wife, and their adult children, but rather an extended family commonly formed by parents, adult sons and daughters and their wives and husbands and their children, grandparents, and other relatives. Married sons usually continue to live with their parents. Typical of Muslim society (Moazam 2006), when a daughter marries, they will often live with their husband's family, while maintaining a strong relationship with their parents' family. Although married sons with their wives or nuclear families seldom move away from the extended (joint) family for socio-economic reasons (e.g., adult children may move for work and business purposes), the vast majority of poor and middle-class Bangladeshis still live with their extended families. The extended family is typically the nuclear family of newly married sons and daughters. This pattern of family generally consists of three or more generations, and is typical of traditional Muslim families (Dhami and Sheikh 2000; Moazam 2006). This is the way that the extended family network builds collective and mutual relationships among its members and each new generation.

Besides blood relations, the only way to form a family in Bangladesh is by marriage. From a religious viewpoint, marriage is defined as the legal union between a husband and a wife. Pre-marital relationships, co-habitation, and same sex-relationships are strongly prohibited (Moazam 2006, 79-80). Within such a society, marriage is arranged in a way such that there is little or no contact between the bride and bridegroom prior to the wedding. The children of married sons and daughters usually have good family relations with each other. Similar to many Muslim societies in South Asia (Moazam 2006), marriage between first cousins is encouraged in Bangladeshi culture, and such marriage is also legal under Islamic law and also the law of the country. However, first cousins are often considered closely related as brothers. Families maintain different levels of contact with their relatives during the marriage of a son or daughter, thereby enhancing the level of integration that occurs between the newly enjoined families. Thus, this practice strengthens family integrity through marriage, and the relationship extends beyond the nuclear family.

The father plays a role as guardian, as in Islamic law men have privilege over women (Quran 4:34). It is very natural for the father to play a familial hierarchical and patriarchal role while the mother practices domesticity and plays a submissive role. Women are primarily responsible for doing household chores and nurturing children. This includes cooking, rearing children, offering social customs and religious norms to their children, teaching good manners and correct conduct, etc. The father assumes the role of provider for his family, as best as he can. The father is expected to provide the family's basic necessities of food, shelter, clothing, and education. Individual family members have a responsibility and owe their existence to the family. The income of the guardian is treated as the income of the whole family, and not as the guardian's personal property. Any expenditure of family members is rightfully met by that family income. This extended network is a good example of "benevolence" and "co-operation" in which everything is shared with members of the family who do not have their own source of income. Though patriarchal ties dominate family life, matriarchal ties are almost as important and are critical 
to the maintenance of familial relationships. It is the married women who provide the greater connectedness between two families (the husband's family and the parents' family). This participation maintains the connectedness and integration of the extended family. This integrity promotes a moral value which influences every decision and activity in the daily life of a Muslim family. As a result, this closely knit structure retains each family member within an integrated system, grounded in a collective cultural tradition.

Bangladeshi families are extended networks, and interrelationships between members are very specific. This type of kinship system is common in many traditional societies where relationships are often inherited from the father to the next generation. The terms that define the exact relationships vary within the familial structure. As kinship terms vary from culture to culture (Ball 2002), different societies categorize kinship terms differently (Geertz 1973). Bangladeshis have different kinship terminology from other cultures. In Western society, there are no specific cultural terms for kinship in their languages, and generic terms are used, such as the English words father, mother, brother, sister, grandfather, grandmother, uncle, aunt, and cousin. Kinship terms in Bangladesh are articulated in Bengali (the national language for Bangladeshis), and these terms are very different from English words. For example, baba means father, $m a$ refers to mother, dada is grandfather, dadi is grandmother, nana is the maternal grandfather, nani is the maternal grandmother, mama is the mother's brother, khala is the mother's sister, chacha is the father's brother, and phuphu is the father's sister. Similarly, there is a different term for each type of cousin (father's brother's children = chachato bhai, chachato bon; father's sister's children = phuphuto bhai, phuphuto bon; mother's sister's children=khalato bhai, khalato bon; and mother's brother's children= mamato bhai, mamato bon). Habitually, cousins are often referred to as one's own brother (bhai) or sister (bon), emphasizing the closeness and bonding of these relationships. The richness of this kinship terminology represents the strength of blood ties and is highly relevant to the moral obligation Bangladeshis hold in critical circumstances such as organ donation for transplantation. This paradigm of relationships stretches beyond close relatives to the extended family.

Despite Muslims being sympathetic to assisting those in need and striving to save the life of any fellow human (Quran 5:32), they are encouraged to prioritize close relatives. As the human body and its internal organs are borrowed in a sort of trusteeship from Almighty Allah, humans cannot do as they wish with their bodies and internal organs (Moazam 2011). A Muslim physician, Farhat Moazam, argues that Almighty Allah has defined limits on the use of the body, thus safeguarding it from any harm (Moazam 2011). As saving the life of a close relative by donating an organ is considered a good act in Islam, the religious principles prohibit Muslims from donating bodily organs to strangers. On the other hand, recipients who receive organs from strangers may encounter negative health consequences such as physical and socio-economic harm (Moazam 2011). Islam values and encourages Muslims who donate to their close relatives. Scholars who support this view cite the Quran and Hadith to support their argument. Saving the life of a close relative by donating an organ is more highly valued in Islam. Muslims have a greater moral obligation to donate organs to their very close relatives. This is because generosity 
to close relatives has great value in Islam, and it is a moral duty and obligation (Quran 17:26). Moral obligation varies according to kinship. They emphasize that saving the life of a very close relative is a great reward for the remaining family (Quran 17:23; 24:22). It follows that Muslims are encouraged to assist and protect the lives of very close relatives more than they are those of others. Muslim scholars use the Prophetic teaching in which Muhammad is reported to have said that "the best beloved of Allah is one who loves his family and kin the most" (Moazam 2006, 227). Scholars argue that Prophetic teachings implore Muslims to be sympathetic to every human being but that one's own family should be given priority, because humans should always maintain their dignity even in disease or misfortune (Al-Bar 1996). The Prophetic tradition states that Muslims who love and care for their family and close relatives will in turn be loved most by Allah. So Muslims should always help close relatives before others. This is the basis for the provisions of the Act that only legally allows an individual to donate an organ for transplantation into a close relative in Bangladesh.

Saving the lives of close relatives has great value in Islam as it is considered a "moral injunction from Allah" (Moazam 2006, 77). This injunction is applied to close family relations in which a family member is more valued than other relatives or associations. This moral injunction and obligation to Allah encourages Bangladeshi Muslims to help close relatives first, including when donating organs. Muslims are pleased to save the life of a close relative (Siraj 2016; Moazam 2006). Muslims believe that saving the life of a close relative by donating an organ is akin to saving their own life (Siraj 2016). Furthermore, the kinship terminology binds Muslims to confide in and trust their close relatives more than strangers. This sociocultural ethos thus influences the Bangladeshi government in maintaining a familyoriented character in policy and practice around living organ donation for transplantation, thereby allowing individuals to prioritize family members in the donation of their organs after death.

In Islam, the importance of maintaining family and kinship is paramount. The Quran states "and be careful of [your duty to] God in whose name you demand [your rights] from one another, and [to] the ties of relationship; surely God is ever watchful over you!" (4:1). Most Bangladeshi families are Muslims and so are extended in nature, bound by blood ties. The verse (8:75) of the Quran also states that Muslims who are bound by blood ties are closest to each other. As grandparents, grandchildren and first cousins are blood relatives; the practice of organ donation for transplantation should not be limited only to close relatives. As saving the life of a family member is the second injunction of Almighty Allah, this injunction should not be limited to close relatives. This injunction is acknowledged by the great-grandson of the Prophet Muhammad Imam Sajjad, his fourth successor. In the Treatise on Rights, he clearly states that everyone has rights over each other, and describes the degree of rights of family members over each other as "the rights of your womb relatives are many; they are connected to you in the measure of the connection of the womb relationship. The most incumbent upon you is the right of your mother, then the right of your father, then the right of your child, then the right of your brother, then the next nearest, then the next nearest - the most worthy, then the next most worthy" (Kermalli 2008). Individual right is interpreted in Islam as "duties and 
obligations" (Daar and Al Khitamy 2001), and these "duties and obligations" vary according to the degree of kinship. We must therefore reciprocate our moral obligations to close relatives before extending our obligation to those outsiders of the family. This emphasizes that saving the life of a close relative such as one's mother, father, son, daughter, brother, and sister is of a higher moral obligation than that owed to other relatives such as the paternal and maternal uncle and aunt, grandparents, grandchildren, cousins, and so on. This means that despite the obligation to the father or mother not being equal to that of uncles, aunts, or first cousins, Muslims also have a moral duty and obligation to help their non-immediate relatives such as grandparents, grandchildren, and first cousins.

Islam teaches Muslims to preserve their obligations to the family, specifically to direct kin (Moazam 2006). The obligation to close relatives has great value in Islam because Muslims are encouraged to be kind to their other relatives. As maintaining kin and blood ties is an obligation under the Islamic faith, scholars equally underscore maintaining good relations with relatives, i.e., loving, respecting, helping, and caring for them when they are in need. Muslims are therefore encouraged to practice duty and kindness to their relatives as described in the verse of the Quran (16:90). Helping more distant relatives is also considered a good deed in Islam. As donating an organ to save the life of a close relative is more valued in Islam, similarly, donating an organ to a less close blood relative is also valued and encouraged. Prophetic tradition teaches that Allah rewards those who serve and maintain kinship ties. As saving human life is the priority for Muslims, this statement implies that Muslims have a moral obligation to donate organs to their less close relatives, after prioritizing close relatives.

The issue can be examined from the perspective of Islamic cultural traditions. The foremost place among blood relatives in Islamic society is reserved for the parents (Quran 17:23; 24:22; 16:90). Parents are highly esteemed, their decisions are mostly obeyed, and their commands are taken into serious consideration by other family members. After parents, the next blood relatives are the son; daughter; brothers; sisters; paternal uncles and aunts, maternal uncles and aunts, and their offspring (first cousins); and other non-immediate relatives (e.g., grandparents and grandchildren). This relationship order has a great importance in Islamic culture in which each person mentioned in the Act receives precedence over subsequent people in terms of the priority for receiving organ donations. For this reason, the policy of living organ donation and transplantation in Bangladesh gives priority to very close relatives over other close relatives. For example, first-degree blood relatives and spouses are always encouraged over second-degree blood relatives regarding biomedical practice in Bangladesh. This preference is essential and required as an individual always has more duty and obligation to a very close relative than to other close relatives. This precedence encourages an individual to assist and save the life of a very close relative before another close relative. This Islamic cultural ethos supports the minimal addition to Bangladesh's current policy and the practice of living organ donation and transplantation to grandparents, grandchildren, and first cousins. Thus, the Act maintains family-oriented biomedical policy and practice. The Islamic Fiqh Academy of New Delhi (session of December 8-11, 1989) also emphasized limiting the policy and practice of organ donation for transplantation from living 
donors exclusively to relatives. The reason behind this biomedical policy and practice is that the academy has concerns regarding organ trade, which has been highly prevalent in the countries of South Asian regions for a long time (Atighetchi 2007). Along with the provision of donation to living relatives, Islamic family culture impacts on the stipulations within the revised Act allowing individuals to prioritize family relatives in determining who should receive their organ donation after their death.

Ethical dilemmas arise around the allocation of organ transplantations from living related donors. As mentioned above, a number of third-degree blood relatives; e.g.; grandparents, grandchildren, and first cousins have been added to the existing donor pool (e.g., the father and mother, adult son and daughter, adult brother and sister, husband and wife, and paternal and maternal uncle and aunt) as potential donors listed in the Act (Section 2:4). The Act also redefines the term "close relative" so as to include grandparents, grandchildren, and first cousins as closely related potential donors to donate organs for transplantation (Section 2:4). According to the kinship ideal that is used by Bangladeshi majority Muslim and collective society, grandparents, grandchildren, and first cousins are seen as relatives, but they are generally described as non-close blood relatives (Siraj 2016). First cousins are the sons and daughters of the maternal and paternal uncle and aunts. They are typically thought of as distant relatives. It seems unlikely that a non-close relation may encourage them into donating organs to a relative under these circumstances. The kinship relation may encourage first cousins to donate organs to their non-close relatives in families in cases where post-operative care is absent, therefore placing them in a grave medical condition. Conversely, although grandparents, grandchildren, and first cousins are considered extended family in Bangladesh, first cousins typically do not share accommodation and/or economic resources. Thus, to prohibit first cousins from receiving financial compensation under the justification that the practice is "paternalistic" is both "unrealistic" and "unfair," the donor and their family should still be protected from the harms and potential health risks involved and should receive the necessary healthcare to support the organ donation process. The description of "it was the best of times, it was the worst of times" by Charles Dickens in $A$ Tale of Two Cities can be metaphorically used in the practice of organ transplantation (Cate 1994, 69) in Bangladesh where only in cases where the organ recipient has a family relationship to the donor may benefits be received, whereas first cousin donors must sacrifice themselves. Donating organs for the sole benefit of someone else and placing potential organ donors in a grave medical condition is unethical and unfair because the practice does not abide by the biomedical principle of nonmaleficence, namely to abstain from doing harm (Childress and Beauchamp 2009). Because the principle of non-maleficence holds that there should be an obligation to society or to the organ recipient, this is an obligation not to inflict harm on the donor's health. Non-maleficence is an important obligation of morality and medical ethics (Al-Bar and Chamsi-Pasha 2015). Islamic scholars argue that harm should be deterred and avoided as much as possible in support of the Prophet Muhammad's verse that says, "There should be no harm or reciprocation" (Al-Bar and ChamsiPasha 2015). It is the responsibility of society to provide free medical services and a fixed amount of money for the well-being of donors (Al-Bar and Chamsi-Pasha 
2015). Consider the prohibition of giving any financial compensation for post-operative care to the first cousin, in the absence of healthcare coverage in Bangladesh. I argue that offering a fixed compensation for altruistic donations may help them to be protected after transplantations. This will thus help increase the supply of organs for transplantations from living donors. It will also reward the altruism of a first cousin donor while preserving ethical principles, as offering a fixed financial compensation as a gift for the donation of organs is permissible by Islamic scholars (Aksoy 2001).

Secondly, ethical dilemmas arise in the system of allocating organs from a deceased donor. According to the allocation system, priority is given first to a relative or others listed by the donor prior to death (Section 7c:3). Other potential recipients sequentially are a younger person; a critically ill or near-death patient whose life would be saved by the procedure; and a person who is geographically nearby or a short journey away (Section 7c:3). Many argue that this allocation system is unfair with regard to distributive justice (Joo 2013); however, this argument is addressed in a number of ways. The Act prioritizes the wishes of the donor and the health of their family in considering the transplantation of organs. This principle is ethical, at least, in the context of Bangladeshi family-oriented society and the Muslim religious culture. The action of prioritizing the donor's family and wishes is realistic and morally justified because the majority of individuals have a family, and very few do not belong to a family. Furthermore, the action of allocating priority to family members may encourage people to become organ donors in the event of their own death, and especially because saving the life of a relative by donating organs is highly valued and encouraged in Islam (Moazam 2006). Saving a human life is highly valued over death in Islam (Rady, Verheijde, and Ali 2009; Aasi 2003). Organ donation by the deceased is conditionally allowed because cutting the dead body for obtaining organs involves violating bodily integrity (El-Shahat 1999; Golmakani et al. 2005), but it facilitates saving the life of a relative as preferable to the alternative (Moazam 2006). A closely related end-stage organ failure patient (ESOFP) should always receive priority because the costs of ICU and ventilator support of the brain-dead donor for the purpose of preserving the organs for transplantations are generally to be incurred by the donor's family. Many argue on the basis of individual human rights that each individual should have an equal right to receive scarce human organs (Cherry 2005, 2009; OPTN 2015). However, I argue that allocating organs equally to recipients regardless of their relation to the deceased on the ground of individual rights, social justice, or equity would be unethical, unrealistic, and unjustified in Bangladeshi culture. The benefit of giving priority to a relative for receiving organs outweighs the alternative as the incentive of saving the life of a relative is more likely to initiate the practice of vital organ transplantations from brain-dead donors in Bangladesh. As a result, the lives of many ESOFPs in Bangladesh will be saved, as transplantation of vital organs from brain-dead donors is currently non-existent. Therefore, as there is no clause in the Act with regard to financial compensation for the families of brain-dead donors to mitigate, at least, the costs of ICU and ventilator use, the bereaved family will likely not agree to allow their brain-dead relative to donate their organs to non-family members, due to the fear of incurring these costs.

Conversely, many families cannot afford to support the process of transplantation from a deceased relative to a living one, as nearly $25 \%$ of people still live below the 
poverty line (Asian Development Bank 2020) and the current COVID-19 pandemic pushes poor people into extreme poverty (Ovi 2020). Thus, the rate of poverty may rise to $40.9 \%$ as a consequence of the COVID-19 pandemic, and economic vulnerability will increase throughout the country (Ahmed 2020; Shammi et al. 2020). The National Deceased Committee is formed to oversee the progress of organ transplantations from brain-dead donors (Section 7b); it is suggested that the Committee should make recommendations to the Bangladeshi government to consider allowing financial compensation in order to support vulnerable families in obtaining organs from their brain-dead relatives so that they can be donated for transplantation. Otherwise, economically vulnerable families with dying relatives will not agree to organ donation for fear of incurring the cost of ICU and ventilator use that is medically required to support their brain-dead relative such that organs are preserved for transplantation (Siraj 2021).

\section{Concluding Remark}

Public policies must be guided with the aim of increasing the number of organ donations for transplantation, where the benefit of such practice always outweighs the harms. The prioritization policy in regard to organ allocation system does not seem to have morally offended the Bangladeshi sense of fairness, and it may vary between cultures. However, allowing the provision of financial incentives for the relatives of living organ donors such as first cousins, or for the bereaved families of brain-dead organ donors, may be needed and is ethically permissible, especially where healthcare coverage is not commonplace, in order to facilitate increased organ transplantations.

Acknowledgements I would like to thank Professor Ruiping Fan, my PhD thesis supervisor, for his guidance in this study. I would also like to acknowledge the efforts made by Dr Rebecca Susan Dewey of the University of Nottingham to provide editing support.

Funding This study was partially supported by the HKSAR Government Postgraduate Studentship (UGC) in Hong Kong.

Data Availability Not applicable

\section{Declarations}

Competing Interests The author declares no competing interests.

\section{References}

Aasi, Ghulam-haider. 2003. Islamic legal and ethical views on organ transplantation and donation. Zygon 38 (3): 725-734. https://doi.org/10.1111/1467-9744.00531.

Ahmed, Zobaer. 2020. Coronavirus: economy down, Poverty up in Bangladesh. Deutsche Welle, 10 June 2020. https://www.dw.com/en/coronavirus-economy-down-poverty-up-in-bangladesh/a-53759686. Accessed 12 Feb 2021. 
Aksoy, Sahin. 2001. A critical approach to the current understanding of Islamic scholars on using cadaver organs without prior permission. Bioethics 15 (5-6): 461-472. https://doi.org/10.1111/1467-8519. 00254.

Al-Bar, Mohammed Ali, and Hassan Chamsi-Pasha. 2015. Nonmaleficence. In Contemporary Bioethics: Islamic Perspective, 119-28. Cham: Springer International Publishing.

Al-Bar, Mohammed Ali. 1996. Islamic ethics of organ transplantation and brain death. Saudi Journal of Kidney Diseases and Transplantation 7 (2): 109-114.

Ali, Mohammad, Subash Gupta, S.M.A. Zafar, Mamunur Rashid, Muhd Mustaque Husain, Hashim Rabbi, A.H.M. Tanvi Ahmed, K.M. Akhtar, and Hasina Alam. 2014. Initiation of liver transplantation in Bangladesh: report on the first two successful cases. Journal of Health, Population and Nutrition 32 (4): 696-700. https://doi.org/10.3329/jhpn.v32i4.3026.

Asian Development Bank. 2020. Poverty data: Bangladesh. https:/www.adb.org/countries/bangladesh/ poverty. Accessed 13 May 2020.

Atighetchi, Dariusch. 2007. Islamic bioethics: problems and perspectives. Dordrecht: Springer.

Bagheri, Alireza. 2005. Organ transplantation laws in Asian countries: a comparative study. Transplantation Proceedings 37 (10): 4159-4162. https://doi.org/10.1016/j.transproceed.2005.11.016.

Ball, Howard. 2002. The Supreme Court in the intimate lives of Americans: birth, sex, marriage, childrearing, and death. New York: New York University Press.

bdnews24.com. 2017. Bangladesh performs 25th bone marrow transplant in the first-ever centre. bdnews24.com, 13 February 2017. https://bdnews24.com/health/2017/02/13/bangladesh-performs25th-bone-marrow-transplant-in-the-first-ever-centre. Accessed 13 May 2020.

Cate, Fred H. 1994. Human organ transplantation: the role of law. Journal of Corporation Law Fall 1994: 69-90. https://www.repository.law.indiana.edu/facpub/692. Accessed 19 Mar 2021.

Cherry, Mark J. 2005. Kidney for sale by owner: Human organs, transplantation, and the market. Washington: Georgetown University Press.

Cherry, Mark J. 2009. Why should we compensate organ donors when we can continue to take organs for free? A response to some of my critics. Journal of Medicine and Philosophy 34 (6): 649-673. https://doi.org/10.1093/jmp/jhp048.

Childress, James F., and Tom L. Beauchamp. 2009. Principles of biomedical ethics, 7th ed. New York: Oxford University Press.

Daar, Abdallah S., and A. Binsumeit Al Khitamy. 2001. Bioethics for clinicians: 21. Islamic bioethics. CMAJ 164 (1): 60-63.

Dhami, Sangeeta, and Aziz Sheikh. 2000. The Muslim family: predicament and promise. Western Journal of Medicine 173 (5): 352-356. https://doi.org/10.1136/ewjm.173.5.352.

El-Shahat, Yassin Ibrahim M. 1999. Islamic viewpoint of organ transplantation. Transplantation Proceedings 31 (8): 3271-3274. https://doi.org/10.1016/S0041-1345(99)00721-6.

Fan, Ruiping. 2015. Informed consent: why family-oriented? In Family-oriented informed consent: East Asian and American perspectives, edited by Ruiping Fan, 1-23. Dordrecht: Springer.

Geertz, Clifford. 1973. The interpretation of cultures: selected essays. New York: Basic Books.

Golmakani, Mohammad Mehdi, Mohammad Hussein Niknam, and Kamyar M. Hedayat. 2005. Transplantation ethics from the Islamic point of view. Medical Science Monitor 11 (4): RA105-109.

Joo, Ho No. 2013. The organ transplantation act and recent trends in Korea. Asia-Pacific Journal of Public Health 25 (2): 209-213. https://doi.org/10.1177/1010539513476935.

Kermalli, Fatima. 2008. The importance of family ties in the Quran. Morning Call, 26 July 2008. https:// www.mcall.com/news/mc-xpm-2008-07-26-4151857-story.html. Accessed 12 Feb 2021.

Moazam, Farhat. 2006. Bioethics and organ transplantation in a Muslim society: a study in culture, ethnography and religion. Bloomington: Indiana University Press.

Moazam, Farhat. 2011. Sharia law and organ transplantation: through the lens of Muslim jurists. Asian Bioethics Review 3 (4): 316-332. http://scholarbank.nus.edu.sg/handle/10635/144515. Accessed 19 Mar 2021.

OPTN. 2015. Ethical principles in the allocation of human organs. Organ Procurement and Transplantation Network, U.S. Department of Health \& Human Services. https://optn.transplant.hrsa.gov/resou rces/ethics/ethical-principles-in-the-allocation-of-human-organs/. Accessed 12 Feb 2021.

Ovi, Ibrahim Hossain. 2020. Covid-19 fallout: income drops to create $16.4 \mathrm{~m}$ new poor this year. Dhaka Tribune, 24 June 2020. https://www.dhakatribune.com/business/economy/2020/06/24/bangladeshto-have-16-4m-new-poor-in-2020. Accessed 19 Mar 2021. 
Rady, Mohamed Y., Joseph L. Verheijde, and Muna S. Ali. 2009. Islam and end-of-life practices in organ donation for transplantation: new questions and serious sociocultural consequences. HEC Forum 21 (2): 175-205. https://doi.org/10.1007/s10730-009-9095-8.

Shammi, Mashura, Md. Bodrud-Doza, Abu Reza Md. Towfiqul Islam, and Md. Mostafizur Rahman. 2020. Strategic assessment of COVID-19 pandemic in Bangladesh: comparative lockdown scenario analysis, public perception, and management for sustainability. Environment, Development and Sustainability, published online 18 July 2020. https://doi.org/10.1007/s10668-020-00867-y.

Siraj, Md. Sanwar. 2016. Organ donation for transplantation in Bangladesh: policy, practice and ethics. PhD thesis, City University of Hong Kong. https://scholars.cityu.edu.hk/en/theses/organ-donat ion-for-transplantation-in-bangladesh-policy-practice-and-ethics(366a5c87-7c5c-48c5-a 49e-19c2a 3e6c55e).html. Accessed 10 Feb 2021.

Siraj, Md. Sanwar. 2020. Why is family-oriented organ transplantation policy and practice necessary for Bangladesh? Bangladesh Journal of Bioethics 11 (1): 1-8. https://doi.org/10.3329/bioethics.v11i1. 49191.

Siraj, Md. Sanwar. 2021. Deceased organ transplantation in Bangladesh: the dynamics of bioethics, religion and culture. HEC Forum, published online 17 February 2021. https://doi.org/10.1007/ s10730-020-09436-2.

UNB News. 2020. First-ever cadaveric kidney transplant in Bangladesh expected in 'Mujib Borsho'. United News of Bangladesh, 21 January 2020. https://unb.com.bd/category/bangladesh/first-evercadaveric-kidney-transplant-in-bangladesh-expected-in-mujib-borsho/41964. Accessed 18 Dec 2020.

Publisher's Note Springer Nature remains neutral with regard to jurisdictional claims in published maps and institutional affiliations. 